\title{
The University of Alabama at Birmingham (UAB) Raptor method for direct percutaneous endoscopic gastrostomy with jejunal extension tube placement
}

Direct percutaneous endoscopic gastrostomy with a jejunal extension tube (PEG-J) is a useful method of providing nutrition to patients with a variety of gastrointestinal (GI) problems [1,2]. However, placing a PEG-J is difficult, especially when delivering the jejunal extension tube into the jejunum $[1,2]$. Often the J-tube bounces back into the stomach during or shortly after having positioned it endoscopically [1-3]. Indeed, some experts have developed techniques with balloon enteroscopes to block the pylorus and prevent the tube from bouncing back into the stomach [3]. The present report describes a novel and simple method of direct percutaneous endoscopic gastrostomy with PEG-J placement using an extra-long foreign body forceps.

This observational, retrospective, singlearm, open-label, institutional review board-approved case study was conducted at a tertiary care hospital during a 24-month period. It included $17 \mathrm{pa}$ tients ( 9 women; mean age 56 years, range $28-79$ ) whose diagnoses included necrotizing pancreatitis $(n=5)$, gastroparesis ( $n=6)$, complex upper GI surgery $(n=3)$, complex fistula $(n=3)$, and recurrent aspiration pneumonia $(n=1)$.
The direct percutaneous endoscopic gastrostomy with PEG-J technique has five key steps ( $\triangleright$ Video 1): (i) insertion of the PEG; (ii) through-the-PEG insertion of the PEG-J; (iii) use of an extra-long foreign body extraction forceps (Raptor; US Endoscopy, Ohio, USA) to advance the jejunal extension tube into the jejunum ( Fig. 1); (iv) an exchange technique in which the scope is pulled back into the stomach while pushing on the Raptor forceps to hold the jejunal tube in place in the jejunum; and (v) once the scope is in the stomach, removal of the Raptor forceps. If during removal of the forceps, there is a slight pull or misplacement of the jejunal tube, the wide grasping prongs of the forceps can easily be used to grab the body of the tube and push it deeper into the jejunum.

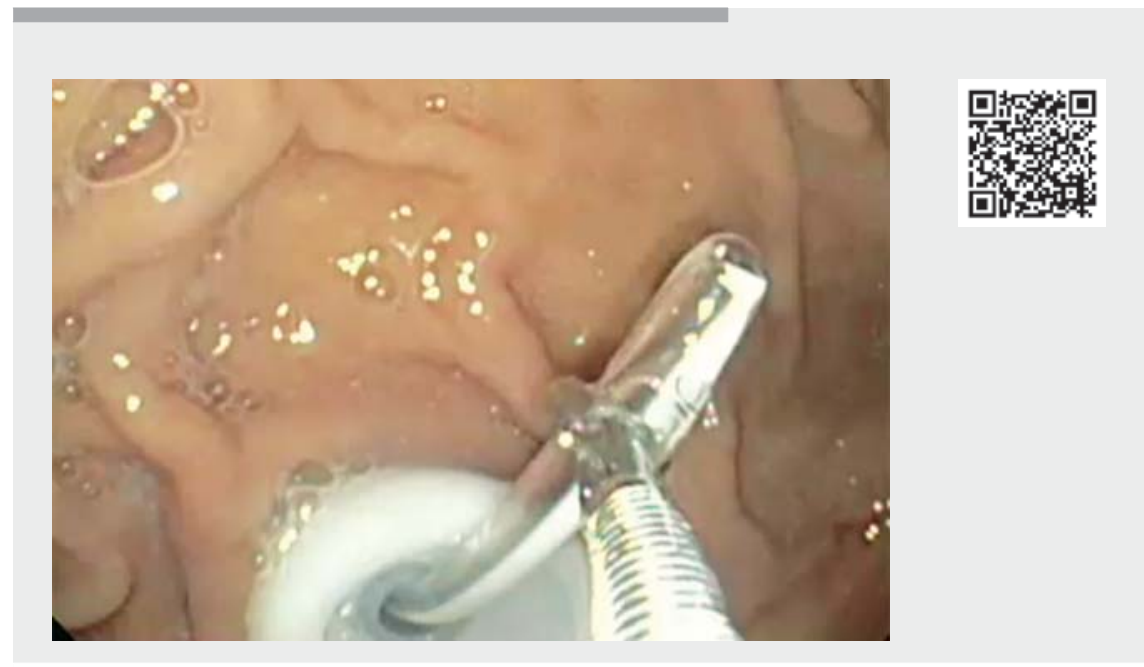

Video 1 Insertion of a direct percutaneous endoscopic gastrostomy with a jejunal extension tube clearly showing the five key techniques involved.
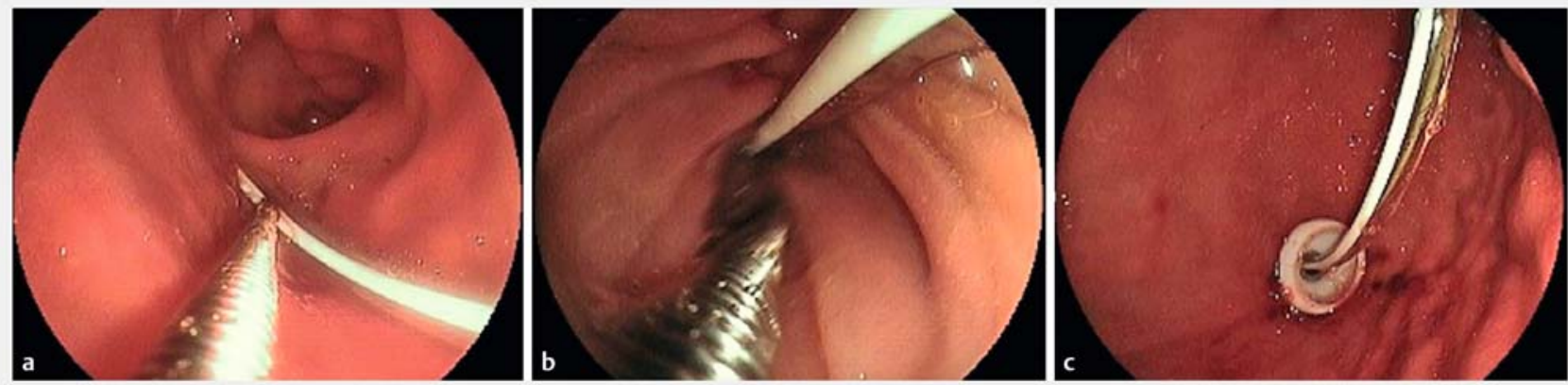

- Fig. 1 Endoscopic views of direct percutaneous endoscopic gastrostomy with a jejunal extension tube (PEG-J) showing: a the J-tube being grasped with the Raptor forceps; $\mathbf{b}$ the J-tube being pushed deeply into the jejunum with the Raptor forceps, where it is held in place while the scope is withdrawn to the stomach; $\boldsymbol{c}$ the final appearance of the correctly placed PEG-J, following retrieval of the forceps only after the scope has been removed back into the stomach. 
Technical success using this technique was $100 \%$. The mean procedure time was 18 minutes (range 15-30). Clinical success was $100 \%$ (17/17); all PEG-Js could be used for feeding purposes. There were no major adverse events. This method of inserting a PEG-J tube with an extra-long foreign body forceps was therefore safe and successful.

This report is interesting for several reasons. First, an extensive literature search did not reveal this practical method of PEG-J placement. Second, this novel method of inserting a PEG-J tube with an extra-long foreign body forceps should be easily reproducible by other endoscopists around the world. Third, we believe that this technique is a useful addition to the armamentarium of every endoscopist. Finally, the teaching video shows all of the steps to accomplish this technique. Future comparative studies are now warranted.

Endoscopy_UCTN_Code_TTT_1AO_2AK

\section{Competing interests}

Klaus Mönkemüller has received honorarium for lectures and consulting from Ovesco, Tübingen.

\section{The authors}

\section{Alvaro Martínez-Alcalá1,2 , Klaus \\ Mönkemüller 2,3,4}

1 Department of Gastroenterology, Hospital Universitario Infanta Leonor, Madrid, Spain

2 Basil I. Hirschowitz Endoscopic Center of Excellence, Division of Gastroenterology and Hepatology, University of Alabama at Birmingham (UAB), Alabama, USA

3 University of Belgrade, Belgrade, Serbia

4 Ameos Klinikum University Teaching Hospital, Halberstadt, Germany

\section{Corresponding author}

Klaus Mönkemüller, MD, PhD

Division of Gastroenterology, University

Teaching Hospital - Ameos Klinikum

Halberstadt, Gleimstraße 5, Halberstadt,

Germany

moenkemueller@yahoo.com

\section{References}

[1] Zhu Y, Shi L, Tang H et al. Current considerations of direct percutaneous endoscopic jejunostomy. Can J Gastroenterol 2012; 26: 92-96

[2] Ridtitid W, Lehman GA, Watkins JL et al. Short- and long-term outcomes from percutaneous endoscopic gastrostomy with jejunal extension. Surg Endosc 2017; 31 : 2901-2909
[3] Sey MSL, Gregor H, Gregor ] et al. Insertion of percutaneous endoscopic gastrostomy tubes with jejunal extensions using the "wedge" technique: a novel method to prevent retrograde tube migration into the stomach. Endoscopy 2017; 49: 1251-1255

Bibliography

Endoscopy 2022; 54: E96-E97

DOI 10.1055/a-1388-5247

ISSN 0013-726X

published online 30.3.2021

(c) 2021. Thieme. All rights reserved.

Georg Thieme Verlag KG, Rüdigerstraße 14,

70469 Stuttgart, Germany

ENDOSCOPY E-VIDEOS

https://eref.thieme.de/e-videos

口回 Endoscopy E-Videos is an open access online section, 回: reporting on interesting cases and new techniques in gastroenterological endoscopy. All papers include a high quality video and all contributions are freely accessible online. Processing charges apply (currently EUR 375), discounts and wavers acc. to HINARI are available.

This section has its own submission website at https://mc.manuscriptcentral.com/e-videos 